\title{
Locked-In Syndrome: a Challenge to Standard Accounts of Selfhood and Personhood?
}

\author{
Dan Zahavi $(\mathbb{D}$
}

Received: 16 August 2018 / Accepted: 31 March 2019/ Published online: 10 April 2019

(C) The Author(s) 2019

\begin{abstract}
A point made repeatedly over the last few years is that the Locked-in Syndrome (LIS) offers unique real-life material for revisiting and challenging certain ingrained philosophical assumptions about the nature of personhood and personal identity. Indeed, the claim has been made that a closer study of LIS will call into question some of the traditional conceptions of personhood that primarily highlight the significance of consciousness, self-consciousness and autonomy and suggest the need for a more interpersonal account of the person. I am skeptical about these claims and will in the following argue that the theoretical relevance of LIS for an understanding of selfhood and personhood has been exaggerated.
\end{abstract}

Keywords Locked-in syndrome $\cdot$ Selfhood .

Personhood $\cdot$ Thought-experiments $\cdot$ Self-consciousness

Not that long ago, philosophical discussions of personhood often tended to focus on the question of diachronic

\section{Zahavi $(\square)$}

Faculty of Philosophy, Radcliffe Humanities, Radcliffe Observatory Quarter, University of Oxford, Woodstock Road, Oxford OX2 6GG, UK

e-mail: dan.zahavi@philosophy.ox.ac.uk

e-mail: zahavi@hum.ku.dk

\section{Zahavi}

Center for Subjectivity Research, University of Copenhagen, Karen Blixens Plads 8, DK-2300 Copenhagen S, Denmark identity and on the so-called persistency question. What are the necessary and sufficient conditions that must be met if I am to be identical to a past or future being? Is it the persistency of some psychological feature (beliefs, memories, preferences, etc.), or is my identity through time rather constituted by some brute physical continuity? A standard way to approach these questions was to test and challenge our intuitions by drawing and relying on various thought-experiments, and the literature is filled with detailed discussions of brain-transplantations, fission and fusion cases, malfunctioning teletransporters, etc.

One recurrent worry, however, has been the following: Is it really legitimate to draw substantial philosophical conclusions from the mere fact that certain scenarios are imaginable? Does our power of imagination always track metaphysical possibilities or might our capacity to imagine certain outlandish scenarios simply reflect our ignorance? As Wilkes once remarked, the more ignorant we are, the easier it will seem to imagine something since "the obstructive facts are not there to obtrude" [1].

This is not to suggest that it might not be relevant to consider and think about exceptional cases, since such cases, to quote Gendler, are "indispensable if we wish to avoid mistaking accidental regularities for regularities which reflect a deeper truth about the world" [2]. But as an increasing number of philosophers have argued, rather than losing one's way in thought-experiments, real life deviations might be more instructive. If we are looking for cases that can shake our ingrained assumptions concerning the nature of the mind, neuro- and psychopathology might offer particular rich sources of challenging material. 
Over the years, different conditions and disorders have triggered the interest of those working theoretically on the topic of personal identity. Recently the locked-in syndrome (LIS) has gained increasing attention. LIS is a condition where the patient is conscious and cognitively unimpaired, but paralyzed and unable to communicate verbally. Since the patient often retains control over vertical eye movements and blinking, it is, however, possible to communicate non-verbally by means of eye blinks. As Nizzi et al. argue, rather than discussing fictional cases from the armchair, philosophers (as well as caregivers and medical teams) should learn from real cases of experienced identity and could consequently profit from engaging with and listening to the firstperson reports of patients with LIS [3].

\section{The Clinical Turn}

Taking the clinical turn is an obvious move to make, but it is also a move that is beset with its own challenges. First, empirical findings are open to interpretation. The interpretation will typically depend upon the theoretical framework within which one is operating. The theoretical impact of an empirical case is consequently not necessarily easily determined. As a case in point, consider schizophrenic thought-insertion, which for a number of years has been discussed by philosophers interested in the question of whether experiential episodes by necessity are characterized by what is sometimes called a sense of ownership. To this day it continues to remain controversial whether episodes of schizophrenic thought-insertion do constitute relevant counter examples [4-6]. To make headway on this question, one cannot make do with either empirical descriptions or abstract theorizing, rather it will be crucial to combine both in a careful and philosophically refined psychopathological investigation.

Second, when dealing with clinical cases that affect and involve issues of experience, it is crucial not simply to leave the interpretation of the cases to the medical personnel. The so-called disability paradox constitutes a stark and dramatic illustration of this point. As has been persistently reported, although most external observers judge individuals with serious and persistent disabilities to live an undesirable or even miserable life, when asked themselves, those very individuals often report that they experience a good or excellent quality of life [7]. This also holds true for patients with LIS. To most outside observers, including trained clinical personnel, LIS might appear to amount to a catastrophic condition with continuous suffering and poor quality of life. But when asked, the patients often rank their quality of life much higher than expected. Some even claim that their quality of life is higher than before the onset of their illness. ${ }^{1}$ The disability paradox is a stark reminder of not conflating empathy with imaginative perspective-taking. To empathically understand the other is not simply a question of imagining what it is like for oneself to be different. This is a point that was made forcefully by classical phenomenologists such as Husserl, Stein and Scheler [9-12]. It is also a point that more recently has been made by feminist theorists such as Young and Spelman:

Generally speaking, able-bodied people simply fail to understand the lives and issues of people with disabilities. When asked to put themselves in the position of a person in a wheelchair, they do not imagine the point of view of others; rather, they project onto those others their own fears and fantasies about themselves. Thus more often than not, well-meaning, able-bodied people seeking to understand and communicate with a disabled person express the patronizing attitudes of pity that so enrage many people with disabilities. As I will discuss later, with careful listening, able-bodied people can learn to understand important aspects of the lives and perspectives of people with disabilities. This is a very different matter from imaginatively occupying their standpoint, however, and may require explicit knowledge of the impossibility of such a reversal [13].

While I am perceiving someone, I must be prepared to receive new information all the time, to adapt my actions accordingly, and to have my feelings develop in response to what the person is doing, whether I like what she is doing or not. When simply imagining her, I can escape from the demands her reality puts on me and instead

\footnotetext{
${ }^{1}$ One striking example is Danny Furlong, who writes "In some ways becoming a mute quad was a boon. I had been a very active person with all sorts of stuff on the go. In hindsight I see I was also quite selfabsorbed and self-centred. So with nearly all of life's demands, diversions, and pursuits stripped away I became a better person, investing much more in others." [8].
} 
construct her in my mind in such a way that I can possess her, make her into someone or something who never talks back [14]. ${ }^{2}$

When considering clinical cases, it is consequently urgent to consider and incorporate the patient's own perspective on the matter, rather than simply projecting and imposing our own prejudices. But this brings me to the third and final challenge I would like to mention. How do we obtain and solicit a comprehensive reply from the patient? The way we pose the questions, the way the interview is conducted, is obviously of central importance. If the questions involve difficult or slippery technical terms, including terms such as identity, self, person, empathy, shame, etc. it is of paramount importance that the terms are understood in a similar way by both patient and interviewer, otherwise the patient might be taken to express opinions that are completely at odds with the patient's actual view on the matter. But if one really wants to be sure that the patient has a solid grasp of what the term means, simple questionnaires with a yes-no option or with a four-point Likert scale are far less suitable than semi-structured interviews, that allow for follow-up questions.

Consider, as an example, a questionnaire adopted and adapted by Nizzi et al. in order to determine experienced personal identity, body representation and experienced meaning in life in LIS patients [3]. By blinking a

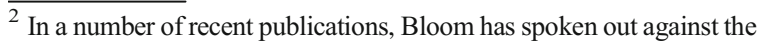
idea that empathy is a moral virtue, something we should strive to nourish and nurture. Bloom offers various reasons for this conclusion, one of which is that empathy involves a kind of affective sharing: to empathize with another person in pain or distress is, according to Bloom, to feel what the other person is feeling. But if the empathizer suffers as a result of empathizing with your suffering, this is not to your obvious advantage. If you seek help from a physician or therapist, you don't want the other to relive your pain and distress, you don't want the other to be overwhelmed by negative emotions, rather you want the other to remain calm and to respond with care and concern and help [15]. As a result, Bloom suggests that limiting our impulse toward empathy might be the most compassionate choice we can make. Given the definition of empathy employed by Bloom, this line of reasoning might seem compelling. The problem, though, is that his definition of empathy as involving an affective match between target and empathizer is controversial. It would lead too far to discuss this topic in further detail here, so let me simply point out that the research literature also contains quite different accounts of empathy. On one of these alternative approaches, empathy is not a question of me having the same mental state as the other, but a question of me becoming acquainted with an experience that is not my own. On this approach, empathy is not about creating similarity, is not about projection, fusion or identification, but about becoming acquainted with the other in a way that preserves his or her difference $[12,16]$. If this is what empathy is, it seems of crucial importance, not only for everyday life, but also for clinical practice.
}

suitable number of times, the patients were asked to answer whether they totally agreed, agreed, disagreed or totally disagreed with the questions that were posed to them. Among the items one can find question such as "My life has ended the day of the accident", "I am still the same person", "I have changed". The first question is distinctly odd, and it is hard to see how anybody could affirm it without committing a performative contradiction: If it is $m y$ life, it obviously didn't end back then. Perhaps it could be objected that the question obviously seemed meaningful to the patients, and that they by answering the way they did were seeking to express how they experienced matters. This is surely right. The problem, though, is that it by no means is obvious what exactly these experiences amounted to. The same holds true for the answers to the two latter questions. According to the authors, the questions were asked in order to determine continuity vs. discontinuity in personal identity [3], but is that really what the patients were addressing or were they simply commenting on the presence or absence of personal change and transformation? Perhaps it could be objected that this is a distinction without a difference, but as anybody familiar with the philosophical debates on personal identity will know, this is hardly true [17]. One important outcome of these latter debates is a number of conceptual distinctions that are important to keep in mind. Consider first the distinction between type identity and token identity. Two objects, say, two tennis balls, might have the same kind of properties, might be qualitatively identical, while still being numerically distinct. In short, they can be different tokens of one and the same type. Consider next the difference between synchronic identity and diachronic identity. It is one thing to ask what constitutes an object's identity at a given time (what makes it different from other objects), and quite another thing to ask what constitutes an object's identity over time, i.e., what makes it the case that a certain object at $t_{1}$ is the same object at $t_{2}$. Importantly, an entity can remain numerical identical over time without remaining qualitatively identical. A dramatic change of properties is fully compatible with a preservation of numerical identity. The car I drive in today does unfortunately not have precisely the same properties as the car I bought 10 years ago. But it is not a numerically distinct car. It is the very same car, which as a result of becoming older and more used have also changed various of its properties.

Considering the plethora of available definitions of selfhood and personhood, considering the presence of 
persisting disagreements among and between philosophers and psychologists on what personal identity amounts to, it is unfortunately far from clear what exactly the patients are saying when they affirm or deny that they have changed or that they are the same person as before. An admission of personal change or transformation cannot without further ado be taken to express an experienced cessation of personal diachronic identity and persistency.

I will return to some of these issues in the following sections. My point for now is simply that just as it is important to solicit first-person reports from the patients under examination, one must also think very carefully about what questions to ask and about how one is asking them. If it is at all possible - and I do, of course, realize that there might be huge practical obstacles in the case of LIS patients - conducting semi-structured interviews will be far more valuable and relevant than simple preformatted questionnaires, since the former will allow one to return to the same issue in different ways thereby permitting further clarification.

\section{Selfhood and Personhood}

Let me return to the question of self- and personal identity. As already mentioned, a point made repeatedly over the last few years is that LIS offers unique real-life material for revisiting and challenging certain ingrained philosophical assumptions about the nature of personhood and personal identity. Indeed, the claim has been made that a closer study of LIS will call into question some of the traditional conceptions of personhood that primarily highlight the significance of consciousness, self-consciousness and autonomy and suggest the need for a more interpersonal account of the person. I am skeptical about these claims, and to anticipate my conclusion, I think the theoretical relevance of LIS for an understanding of selfhood and personhood has been exaggerated. To substantiate this claim, let me take a critical look at two of the contributions to the present special issue, namely the paper by Nizzi, Blandin and Demertzi, and the paper by Kyselo.

In their article "Attitudes towards personhood in the locked-in syndrome: from third- to first-person perspective and to interpersonal significance", Nizzi, Blandin and Demertzi argue that whereas patients with LIS from a third-person perspective might be expected to experience a change of personal identity, and perhaps even lose their status as persons, this is not at all borne out by first-person reports. From the patients' perspective, "it is uncontested that they retain their personal identity and they consider themselves as persons" [18]. But as the authors then, somewhat surprisingly, add: "personhood in LIS is progressively regained as the widening circle of others recognizes them as persons" [18]. I find this a puzzling claim, and I wonder whether it doesn't involve a conflation of two quite different normative conceptions of personhood.

According to the first, which is briefly referenced by Nizzi and her colleagues in the very abstract of their paper, personhood is a legal notion with normative implications. On such an account, you cannot be a person on your own. Rather, personhood is ascribed to you by others and is associated with rights and responsibilities (and might to that extent be compared to citizenship). According to the second conception, however, personhood is not primarily a question of how others treat you but is rather a matter of your own normative commitments. When you commit yourself to taking certain attitudes as the normative basis from which to reason and act, when you live a life in accordance with self-imposed guidelines, you come to have your own distinct point of view on matters and, thereby, your own personal identity $[34,35]$. On this latter conception of personhood, one might well argue that sociality plays a very central role - after all, our values and norms do not emerge in a vacuum but are very much dependent on the community of which we are part. The two views nevertheless differ radically when it comes to the case of LIS. Whereas the former conception of personhood might indeed be one that the patient gradually gains or retrieves on the basis of being recognized by others, it is harder to make sense of the idea that this also holds true for the latter. Yet that does seem to be the view defended by the authors. So, on this view, the idea is not simply that in order to become persons we have to be supported by a suitable social environment, and that the process of socialization is to that extent a crucial developmental prerequisite for personhood. No, the view is the far more radical one that we can only be said to possess and retain personal identity if others continuously affirm it. Indeed, the authors explicitly endorse an interpersonal account of personhood according to which the personhood of an individual is constitutively dependent upon others. It is the attitudes of others that assign and deprive personhood to a subject. If the 
patient is not recognized and treated as a person by others, she will not be a person, she will have no personal identity [18].

I am obviously not questioning the idea that the attitudes of others, their respect and esteem can be of central significance for the patient's quality of life. This is also borne out by the fact that the latter is typically strongly dependent upon the quality of communication. Indeed, patients with LIS usually only report high quality of life after stable channels of communication have been reestablished [19]. Being spoken about in one's presence, being treated not as a co-subject, but as an object, being spoken to as if one is deaf or slow-witted, being asked questions, where the questioner doesn't wait for and doesn't seem to expect any answer, all of this can obviously be quite demeaning. But there is an important difference between saying that my social status as well as my self-esteem are influenced by how others treat me, and arguing that my personal identity is dependent upon social interaction to such an extent that I will cease being a person if the latter is interrupted. As far as I can see, the authors' do not offer any arguments to support this radical view. Nizzi, Blandin and Demertzi quote Mournier, who argued that being a person is different from being an object [20]. I agree and have been making a similar argument for a long time [12, 21, 22], but it certainly doesn't follow from this view that I cease being a person the moment others treat me as an object. In fact, it is precisely because I remain a person with a certain preserved amount of selfrespect that I might feel demeaned and humiliated by being treated as an object by others. Had I in fact no longer remained a person, but been reduced to a mere object, I would have been quite indifferent to the way others were treating me.

More generally speaking, I don't understand why Nizzi, Blandin and Demertzi suggest that our respect for the patient rather than being based on an appreciation of the patient's current capacities should be based on an obligation towards the patient that is rooted in what he or she was prior to the onset of the illness [23]. Whereas this might perhaps be an appropriate stance towards patients in a vegetative state, I find it quite strange to adopt it in the case of LIS, since that condition is precisely characterized by preserved awareness and cognition. To base one's interaction with LIS patients on a respect for what they used to be, rather than on what they currently are, strikes me as fundamentally misguided.
At one point in their text, Nizzi, Blandin and Demertzi write that the fact that the "patients' bodies continue to live after their accidents" imply that the "identity in patients in LIS is primarily socially constituted" [23]. This is once again, a rather puzzling claim. One way to interpret it, however, is as follows. Since the identities of the patients' bodies persist and since the identities of the patients with LIS are disrupted, the latter cannot be based on brute bodily persistency, but must instead be socially constituted. If this is indeed the argument, it is a non sequitur, since a social constructivist account of personal identity and persistency is hardly the only alternative available. But more importantly, does LIS really present us with cases of disrupted identity? As should be clear from what I written above, I don't find it obvious that it does. For sure, LIS does present us with cases where the life-situation of the individual has changed radically. It is not merely the case that the individual's mobility and agency is profoundly affected, or that the quality and quantity of communication and social interaction have diminished. It might also be the case, as for instance brought out in Dudzinski's discussion of the case of Jean-Dominique Bauby, that the patient's self-experience is transformed as a result of a fundamental bodily self-alienation, since the body is increasingly felt as a prison rather than as a part of oneself [24]. However, in spite of these important changes, there is as far as I can see no reason to accept the claim that patients with LIS have either lost their (synchronic) self-identity or personal identity, i.e., that they as a result of LIS are no longer selves or persons, or that their diachronic self- or personal identity have been disrupted, such that they are no longer the numerical same person or self that they were prior to the accident. $^{3}$ A patient with LIS remains perfectly capable of cherishing and endorsing (communally based) values and normative commitments, and continues to be able to appropriate past experiences into a unifying narrative. In short, were I to become afflicted with LIS, it is neither the case that I cease being a self or person, or that I cease being the same self or person. Radical changes in life circumstances can occasion changes in our selfunderstanding and self-appraisal. When our capacities change, when our beliefs, ideas, aspirations change, then

\footnotetext{
3 There are, of course, plenty who deny the existence of any diachronically persisting self, but in the present context I will not take issue with their arguments, and only focus on those who think that diachronic persistency is a particular problem for patients with LIS.
} 
so do we. But, as already pointed out, qualitative change is compatible with a preservation of numerical identity.

\section{Is the Self an Interpersonal Construct?}

So far, I have been using the terms 'self' and 'person' interchangeably. Let me at this point differentiate between the two and stipulate the following distinction. I will continue to use the notion of person in the normative sense outlined above. The notion of self, however, will from now on be used to target the first-personal character of consciousness. On this construal, the self is something that is essentially present in each and every experience. It is present, not as a separately existing entity, i.e., as something that exists independently of, in separation from or in opposition to the stream of consciousness. Nor is it given as an additional experiential object or as an extra experiential ingredient, as if there were a distinct self-quale, next to and in addition to the quale of the smell of burnt hay and roasted almonds. No, the claim is that all experiences regardless of their object and regardless of their act-type (or attitudinal character) are subjective in the sense that they necessarily come with a point of view, with what has occasionally been called perspectival ownership. On this account, the subject of experience should not be conceived as an independent, detachable entity, but as the very subjectivity of experience, which is something no experience can lack, neither metaphysically, nor phenomenologically. To use a formulation of Strawson's, if experience exists, subjectivity exists, and that entails that subject-of-experience-hood exists [25]. Phenomenally conscious episodes are not simply occurring in a subject but are for a subject, or to put the same point differently, the what-it-is-likeness of phenomenally conscious mental states is in reality a what-it-is-like-for-me-ness $[6,12$, 22].

Assuming for the sake of the argument, that this is a legitimate use of the notion of self, is there then any reason to assume that that kind of selfhood is affected or inflicted in patients suffering from LIS? As already pointed out, despite the global paralysis and the dramatically changed life situation of the patients, they remain conscious. There is no cessation of the stream of consciousness, no destruction of the first-person perspective, no inability to remember past pre-accident experiences "from the inside". In short, the patients remain synchronic and diachronic experiential unities. They are not only selves at any given moment of experience (i.e. synchronically), but they are also diachronically persisting selves, at least to the same degree as healthy subjects are.

This account is, however, one that Kyselo takes issue with in her contribution "More than our body: Minimal and enactive selfhood in global paralysis". In her view, the idea that somebody can remain a self in cases where the character and nature of social interaction is diminished or even completely absent is an idea that is distinctly linked to Western culture and to its privileging of the autonomous independent individual [26]. ${ }^{4}$ For Kyselo, being a self - even as minimal a self as the one just outlined - is to distinguish oneself from others, and this is not something we do on the basis of ontological or physiological boundaries, but on the basis of processual and organizational ones. If we are prevented from interacting with the world and with others, we cannot enact our self, we cannot partake in the very dynamics that is required in order to bring about our sense of self as a separate subject. This is why Kyselo insists that selves are essentially social, and why she in regard to LIS can write that "Family, friends, doctors and care-givers - all form part of the social sphere that acts as the concrete background for the patient's ability to maintain her sense of self" [26], and why she argues that patients by losing connection to the social sphere risk "losing parts of the very mechanism and conditions that bring about their self" [26]. How exactly is this argument supposed to run? Given that Kyselo seems to accept both that phenomenal consciousness involves for-me-ness and that for-me-ness is sufficient for a minimal type of selfhood, the only way to maintain the claim that selfhood depends upon social interaction would be by showing that phenomenal consciousness, i.e., our very having of experiences, are constitutively dependent upon social interaction [28]. Kyselo initially accepts that challenge, and in her article proposes that one can find claims to that effect in the work of

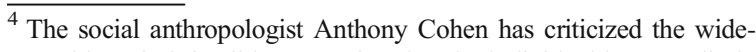
spread but "indefensible contention that the individual is a peculiarly Western concern". As he points out, not only does such a contention, commit the mistake of denying the concepts and values of individuality to non-Western cultures, but it also involves the implementation of a much too crude dichotomization between individualistic and holistic societies [27]. According to Cohen, the mistake is based on a failure to distinguish properly between individuality and individualism. Individualism, on his view, is a position that privileges the individual over society. To talk of individuality, by contrast, is simply to recognize the distinctiveness of an individual.
} 
Heidegger and Merleau-Ponty. It would lead too far to discuss every step of Kyselo's interpretation of MerleauPonty and Heidegger, but as I read her, her main accomplishment is to show that both thinkers deny the existence of a non-social self. Regardless of whether this interpretation is warranted, it doesn't provide the missing arguments. At best it is merely an argument from authority. Establishing that Merleau-Ponty at one point defended the view that the self emerges out of a primary relational connectivity to others is quite different from establishing that the view is correct. ${ }^{5}$

For Kyselo "human selfhood is socially and interactively constituted". She insists that the constitutive dependency in question doesn't only hold true in early development, but rather extends to all later stages in life, such that a "constitutive social dynamics" is "required for the maintenance of the sense of self" [26]. On her view, selfhood consequently depends upon "ongoing social relations and interactions" [26]. I am not persuaded. We need to distinguish a de facto interdependence from a constitutive interdependence. It is one thing to argue that we - i.e., us human beings - de facto are situated in and interacting with a social world, and something else to argue that our very capacity to have experiences is constitutively dependent upon such interaction. Furthermore, what is ongoing social interaction supposed to cover? If it means real-time interaction with other social agents, then the claim that self-experience depends upon such interaction is obviously false.

Consider, for example, the case of Tenzin Palmo. She grew up in London and initially worked as a librarian. But when she turned 20, she moved to India, and shortly after her 21st birthday she became a Buddhist nun. After many years of meditation, her teacher encouraged her to go and practice at a monastery in the mountain region of Lahaul. Tenzin Palmo eventually found the monastery too noisy, and when she turned 33, she decided to retreat to a nearby cave where she lived for 12 years, the last 3 of which was spent in complete solitude [33]. Tenzin

\footnotetext{
$\overline{{ }^{5} \mathrm{I} \text { have offered }}$ an extensive discussion and somewhat divergent interpretation of Merleau-Ponty's [29, 30] and Heidegger's [31] position elsewhere. Let me here merely add that it even among phenomenologists remains controversial whether Heidegger's account of Mitsein and Miteinandersein really succeeds in capturing the importance of sociality. As Levinas observes: "The relationship with the Other is indeed posed by Heidegger as an ontological structure of Dasein, but practically it plays no role in the drama of being or in the existential analytic. All the analyses of Being and Time are worked out either for the sake of the impersonality of everyday life or for the sake of solitary Dasein" [32].
}

Palmo's tale might be exceptional, but it is by no means unique. Withdrawing from society and sociality and seeking solitude has for centuries been an established religious practice. But would it be appropriate to say that Tenzin Palmo ceased being a self, ceasing having a selfidentity, when she was living on her own? Judging from her own description, Tenzin Palmo very much found fulfilment in the retreat, and in the interview in The Guardian expressed a desire to return to her solitary retreat.

\section{Conclusion}

If we return for a moment to the normative conception of personhood, I am not disputing the role of sociality. We would not be who we are, we would not have the normative commitments we have, were it not for the social relationships we engage in. To that extent, we might indeed be said to be constitutively involved in each other's lives. But acknowledging this does not entail that we cease being persons the moment we are deprived of social interaction or the moment others stop recognizing us as persons. I am also not disputing that ongoing social interaction is often - but as the case of Tenzin Palmo just illustrated, not always - crucial for leading a qualitatively rich meaningful life. As studies of patients with LIS have shown, their quality of life is typically correlated with the character of their interpersonal relation. But this does not prove that the latter is essential for (the experience of) personhood or selfhood.

If one is on the lookout for changed life situations with a potential impact on personal identity, it is by no means obvious that LIS is the best and most dramatic case to consider. Not only are there many other conditions that can lead to self-transformation, such as becoming blind, being disfigured by acid, surviving three years in a $\mathrm{KZ}$ camp or undergoing a religious conversion, but there are also various disorders of consciousness, including Alzheimer's disease and dementia, schizophrenia, Cotard's syndrome and dissociative identity disorder, which are far more relevant, if we want to consider clinical cases that can challenge our standard conceptions of self and identity.

If there is something in particular (the study of) LIS can teach us, it might be to appreciate the resilience of human beings and not to operate with too narrow a conception of what a meaningful life entails. 
Open Access This article is distributed under the terms of the Creative Commons Attribution 4.0 International License (http:// creativecommons.org/licenses/by/4.0/), which permits unrestricted use, distribution, and reproduction in any medium, provided you give appropriate credit to the original author(s) and the source, provide a link to the Creative Commons license, and indicate if changes were made.

\section{References}

1. Wilkes, K.V. 1988. Real people: Personal identity without thought experiments, 31. Oxford: Clarendon Press.

2. Gendler, T. S. 1999. Exceptional Persons: On the Limits of Imaginary Cases. In Models of the Self, eds. S. Gallagher and J. Shear, 447-465. Thorverton: Imprint Academic; p. 463.

3. Nizzi, M.-C., A. Demertzi, O. Gosseries, M.-A. Bruno, F. Jouen, and S. Laureys. 2012. From armchair to wheelchair: How patients with a locked-in syndrome integrate bodily changes in experienced identity. Consciousness and Cognition 21: 431-437.

4. Billon, A. 2011. Does consciousness entail subjectivity? The puzzle of thought insertion. Philosophical Psychology 26 (2): 291-314.

5. Guillot, M. 2017. I Me Mine: On a confusion concerning the subjective character of experience. Review of Philosophy and Psychology 8: 23-53.

6. Zahavi, D. 2018. Consciousness, self-consciousness, selfhood: A reply to some critics. Review of Philosophy and Psychology 9: 703-718.

7. Albrecht, G.L., and P.J. Devlieger. 1999. The disability paradox: High quality of life against all odds. Social Science \& Medicine 48: 977-988.

8. Pedler, C. 2014. Danny's will to write. Bendigo Advertiser http://www.bendigoadvertiser.com.au/story/2370299 /dannys-will-to-write. Accessed July 20, 2018.

9. Husserl, E. 1989. Ideas pertaining to a pure phenomenology and to a phenomenological philosophy, book 2, studies in the phenomenology of constitution, trans. R. Rojcewicz and A. Schuwer. Dordrecht: Kluwer Academic Publishers.

10. Stein, E. 1989. On the Problem of Empathy, trans. W. Stein. Washington, DC: ICS.

11. Scheler, M. 2008. The nature of sympathy, trans. P. Heath. London: Transaction.

12. Zahavi, D. 2014. Self and other: Exploring subjectivity, empathy, and shame. Oxford: Oxford University Press.

13. Young, I. M. 1997. Asymmetrical reciprocity: on moral respect, wonder, and enlarged thought. Constellations 3/3: 340-363; p. 344.

14. Spelman, E. 1988. Inessential woman, 181. Boston: Beacon Press.

15. Bloom, P. (2014). Against empathy. Boston Review 39/5: 14-19.

16. Ratcliffe, M. 2014. Experiences of depression: A study in phenomenology. Oxford: Oxford University Press.

17. Olson, Eric T. 2017. Personal Identity. In The Stanford Encyclopedia of Philosophy (Summer 2017 Edition), ed. Edward N. Zalta. https://plato.stanford. edu/archives/sum2017/entries/identity-personal/. Accessed online July 20, 2018.

18. Nizzi, M.-C., V. Blandin, and A. Demertzi. 2018. Attitudes towards personhood in the locked-in syndrome: From third- to first-person perspective and to interpersonal significance. Neuroethics; p.1. https://doi.org/10.1007/s12152-018-9375-6.

19. Bernat, J.L. 2018. Medical decision making by patients in the locked-in syndrome. Neuroethics. https://doi. org/10.1007/s12152-018-9358-7.

20. Nizzi, M.-C., V. Blandin, and A. Demertzi. 2018. Attitudes towards personhood in the locked-in syndrome: From third- to first-person perspective and to interpersonal significance. Neuroethics; p.7. https://doi.org/10.1007/s12152-018-9375-6.

21. Zahavi, D. 1999. Self-awareness and Alterity: A phenomenological Investigation. Evanston. Northwestern University Press.

22. Zahavi, D. 2005. Subjectivity and selfhood: Investigating the first-person perspective. Cambridge: MIT Press.

23. Nizzi, M.-C., V. Blandin, and A. Demertzi. 2018. Attitudes towards personhood in the locked-in syndrome: From third- to first-person perspective and to interpersonal significance. Neuroethics; p.3. https://doi.org/10.1007/s12152-018-9375-6.

24. Dudzinski, D. 2001. The diving bell meets the butterfly: Identity lost and re-membered. Theoretical Medicine 22: 33-46.

25. Strawson, G. 2009. Selves: An essay in revisionary metaphysics, 419. Oxford: Oxford University Press.

26. Kyselo, M. 2019. More than our body: Minimal and enactive selfhood in global paralysis. Neuroethics, in press.

27. Cohen, A. 1994. Self-consciousness: An alternative anthropology of identity, 14-15. London: Routledge.

28. Zahavi, D. 2017. Thin, Thinner, Thinnest: Defining the Minimal Self. In Embodiment, Enaction, and Culture. Investigating the Constitution of the Shared World, eds. C. Durt, T. Fuchs, C. Tewes, 193-199. Cambridge: The MIT Press.

29. Zahavi, D. 2002. Anonymity and first-personal givenness. An attempt at reconciliation. In Subjektivität Verantwortung - Wahrheit, eds. David Carr \& Chr. Lotz, 75-89. Frankfurt am Main: Peter Lang.

30. Zahavi, D. 2015. Vindicating Husserl's primal I. In Phenomenology in a new key: Between analysis and history, ed. J. Bloechl and N. de Warren, 1-14. Dordrecht: Springer.

31. Zahavi, D. 2003. How to investigate subjectivity: Natorp and Heidegger on reflection. Continental Philosophy Review 36 (2): 155-176.

32. Levinas, E. 1987. Time and the other, trans. R.A. Cohen. Pittsburgh: Duquesne University Press; p. 40.

33. Powell, L. 2009. I spent 12 years in a cave. The Guardian. https://www.theguardian.com/lifeandstyle/2009/may/15 /buddhist-retreat-religion-first-person. Accessed online July 20, 2018.

34. Korsgaard, C.M. 2009. Self-constitution: Agency, identity, and integrity. Oxford: Oxford University Press.

35. Rovane, C. 2012. Does rationality enforce identity? In The self and self-knowledge, ed. A. Coliva, 17-38. Oxford: Oxford University Press.

Publisher's Note Springer Nature remains neutral with regard to jurisdictional claims in published maps and institutional affiliations. 